\title{
Transcatheter Aortic Valve Implantation: Experience of Sainte Clotilde Hospital in Reunion Island
}

\author{
Adam Ahamat Ali1,2*, Christophe Pouillot ${ }^{3}$, Geoffrey Rambaud ${ }^{3}$ \\ ${ }^{1}$ Cardiology Department, Renaissance Hospital of N'Djamena City, N’Djamena, Chad \\ ${ }^{2}$ Faculty of Human Health Sciences of N'Djamena City, N'Djamena, Chad \\ ${ }^{3}$ Cardiology Department, Sainte Clotilde Hospital, Reunion Island, France \\ Email: *aliadamahmat@hotmail.com, christophe.pouillot@clinifutur.net
}

How to cite this paper: Ali, A.A., Pouillot, C. and Rambaud, G. (2019) Transcatheter Aortic Valve Implantation: Experience of Sainte Clotilde Hospital in Reunion Island. World Journal of Cardiovascular Diseases, 9, 772-780.

https://doi.org/10.4236/wjcd.2019.910069

Received: August 29, 2019

Accepted: October 28, 2019

Published: October 31, 2019

Copyright $\odot 2019$ by author(s) and Scientific Research Publishing Inc. This work is licensed under the Creative Commons Attribution International License (CC BY 4.0).

http://creativecommons.org/licenses/by/4.0/

\begin{abstract}
Introduction: Degenerative aortic stenosis is the most common valvulopathy in developed countries. The implantation of a percutaneous aortic valve (TAVI) has taken an important place in the management of this valvulopathy. The objective of this work is to report the results of patients treated by TAVI by the team of Sainte Clotilde Hospital (Reunion Island). Patients and Methods: This was a descriptive retrospective study conducted from 01/10/2014 to 01/10/ 2017 in the Sainte Clotilde Hospital, Reunion Island. All patients who received TAVI for degenerative aortic stenosis were included in the study. Follow-up was completed until 31/08/19. Results: Forty-six (46) patients were included (sex ratio 0.53$)$. The age was $82( \pm 7.5)$. Respectively, $56.5 \%, 21.7 \%$ and $6.5 \%$ of patients were diabetic $[\mathrm{n}=26(56.5 \%)]$, severe renal impairment $[\mathrm{n}=10(21.7 \%)]$ and hemodialysis $[\mathrm{n}=3(6.5 \%)]$. All procedures were performed by femoral route under consious sedation. Edwards' prostheses were used more often (93\%), 100\% Sapien 3, 6\% of which were size 23. The primary success rate was $97.8 \%$ and the failure rate was $2 \%$ (deaths per procedure). The TAVI range of $0.66 \pm 0.14$ and $46.8 \pm 15.5$ against $1.48 \pm 4.3$ and $13.8 \pm 5$ in post TAVI. Severe pulmonary arterial hypertension $(>60 \mathrm{mmHg}$ ) was observed in $21.7 \%$ of pre-TAVI patients compared to $4 \%$ in post TAVI patients. The overall rate of complications was $17 \%(\mathrm{n}=8)$. They were related to conductive disorders $[6.5 \%(\mathrm{n}=3)]$, paraprosthetic leakage $[2 \%(\mathrm{n}=1)]$, tamponade $[2 \%(\mathrm{n}=1)]$, and hemorrhagic complications $[6.5 \%(\mathrm{n}=3)]$. Mean follow-up was 946 days $($ median $=1007.5$ days), mean follow-up death rate was $30.4 \%(n=14)$. The causes of death were non-cardiac in $57 \%(n=8)$ of the cases. Conclusion: The TAVI results of the Sainte Clotilde Hospital Clinic are comparable to those observed in the literature.
\end{abstract}




\section{Keywords}

Calcified Aortic Stenosis, Percutaneous Valve Replacement, Sainte Clotilde Hospital, Reunion Island

\section{Introduction}

Aortic stenosis (AS) is the most common primary valvulopathy leading to surgical or percutaneous surgery in Europe and North America. Its prevalence increases with the aging of the population [1]. It is a degenerative disease characterized by progressive calcification of the aortic valve (Mönckeberg's disease). In the calcified AS of the elderly, the aortic valve becomes restrictive, the area of the aortic ejection tract decreases and the diastolic pressure of the left ventricle increases [2]. The TAVI was developed in the early 2000s, following the work of Alain Cribier's team, a Cardiology department in Rouen, France. As a result, this technique has progressed rapidly to become the treatment of choice for severe aortic stenosis in high-risk or inoperable patients [3]. In recent years, we have seen an increase in the number of TAVI and the broadening of the spectrum of their medical indications [4]. The implantation of TAVI in patients at low to intermediate risk is one of the major transitions observed in recent years [5]. The first TAVI was performed in Reunion in October 2014 by the team of Dr. Christophe Pouillot of the Sainte Clotilde Hospital ( $\mathrm{SCH}$ ). The objective of this work is to report the results and the follow up of the patients who received TAVI by the SCH team (50th center in France TAVI).

\section{Patients and Method}

This is a retrospective, descriptive study carried out from 01/10/2014 to 01/10/ 2017 at SCH. Every patient who got a TAVI during this period was included in the study. The selection of our patients was based on the European Society of Cardiology recommendations [1]. They were recruited through the consultation or were sent to us by our correspondent cardiologists city.

The pre-TAVI assessment included: echocardiography, coronary angiography, supra-aortic trunk ultrasonography, thoracoabdominopelvicangioscan, respiratory function test, and dental care. The TAVI indications were validated by a multidisciplinary staff (heart team).

The interventions took place in the hybrid room of the Reunion University Hospital in presence of anesthesiologists and cardiac surgeons.

The TAVI was performed according to the following technique: after puncturing the femoral artery under local anesthesia (xylocaine) and sedation (by neuroleptic), the biological valve mounted on a stent was introduced and then moved foward to the aortic valve. The stent was then deployed in the aortic valve using a balloon (expendable balloon) or dropped to self-deploy. Once the procedure was completed, a cardiac ultrasound was performed to check the functionality of the bioprosthesis and to look for any complications. Then the patient 
was placed in intensive care for 24 hours.

After leaving the hospital, all patients were regularly monitored by their attending physicians and by Dr. Pouillot's team (every 6 months). The monitoring was carried out until 31/08/19.

The following variables were studied:

- Characteristics of the population: sex, age, size, comorbiditties (diabetes, chronic renal failure and hemodialysis).

- Risk score: logistic Euro Score.

- Indications for TAVI: Surgery against Indicated, high operative risk, fragility, surgery refusal.

- Echocardiographic features: Left Ventricle Ejection Fraction (LVEF), Aortic Valve Area (AVA), Mean Trans aortic Gradient (MTAG), and severe Pulmonary Arterial Hypertension (PAH) before and after TAVI.

- Valve type: Edwards Sapien 3, Medtronic Core Valve.

- Success rate.

- During follow up:

Complications.

Death rate.

Causes of death.

\section{Definitions:}

Severe aortic stenosis was defined by: an AVA $<1 \mathrm{~cm}^{2}\left(\right.$ or $\left.0.6 \mathrm{~cm}^{2} / \mathrm{m}^{2}\right)$, MTAG $\geq 40 \mathrm{mmHg}$ or maximum transaortic flow velocity $\geq 4.0 \mathrm{~m} / \mathrm{s}$ (1). LVEF was considered normal if $70 \% \pm 10 \%$.

Severe PAH was defined by systolic pulmonary arterial pressure $>60 \mathrm{mmHg}$.

\section{Statistical analysis}

Quantitative variables were presented by their mean and standard deviation, and qualitative variables by their percentage. The analysis of the efficacy of TAVI was done by comparing pre- and post-test ultrasound data with a student test for continuous variables and a chi-square test for qualitative variables.

\section{Results}

During the period of our study, forty-six (46) patients were included: 16 men $(35 \%)$ and 30 women (65\%). The mean age was $82 \pm 7.5$ years, the sex ratio was 0.53 and the average EuroScore logistic risk score was $28.9 \pm 18.7$. The most common indication for TAVI was high-risk surgery (69.5\%). Table 1 presents the epidemiological and clinical characteristics of the 46 patients. In pre-TAVI, the average ultrasound LVEF was $56.5 \%$, the mean AVA was $0.66 \pm 0.14 \mathrm{~cm}^{2}$, the MTAG was $46.8 \pm 15.5 \mathrm{mmHg}$, there was a severe PAH was in $21.7 \%$ of cases.

Technical caracteristic of the TAVI procedure:

All procedures were performed by femoral route under local anesthesia and neuroleptic sedation. The Edwards Sapien 3 bio prosthesis was more often used (93\%), with $63 \%$ Sapien 3 No. 23. The primary success rate was 97.8\%. The average hospital stay was nine (9) days. Table 2 shows the technical characteristics of the TAVI procedure. 
Table 1. Demographic, anamnestic and ultrasound characteristics of the 46 patients studied.

\begin{tabular}{|c|c|c|}
\hline Characteristics & Frequency & Percentage (\%) \\
\hline \multicolumn{3}{|c|}{ Sex } \\
\hline Men & 16 & 34.7 \\
\hline Women & 30 & 65 \\
\hline \multicolumn{3}{|c|}{ Age (year) } \\
\hline Minimum & 54 & - \\
\hline Medium & $82 \pm 7.5$ & - \\
\hline Maximum & 94 & - \\
\hline \multicolumn{3}{|c|}{ Average size $(\mathrm{cm})$} \\
\hline Men & $157.9 \pm 6.6$ & - \\
\hline Women & $153.6 \pm 6.8$ & - \\
\hline \multicolumn{3}{|c|}{ Comorbidity } \\
\hline Diabetes & 26 & 56.5 \\
\hline Severe renal insuffisancy & 10 & 21.7 \\
\hline Dialysis & 3 & 6.5 \\
\hline Logistic Euro Score & $28.9 \pm 18.7$ & - \\
\hline \multicolumn{3}{|c|}{ Main indication } \\
\hline Surgery Against Indicated & 6 & 13 \\
\hline High operative risk & 32 & 69.5 \\
\hline Fragility & 3 & 6.5 \\
\hline Refusal of surgery & 5 & 10.8 \\
\hline \multicolumn{3}{|c|}{ Echocardiography } \\
\hline LVEF (\%) average & $56.5 \pm 11.3$ & - \\
\hline Mean AVA $\left(\mathrm{cm}^{2}\right)$ average & $0.66 \pm 0.14$ & - \\
\hline MTAG (mmHg) & $46.8 \pm 15.5$ & - \\
\hline Severe PAH & 10 & 21.7 \\
\hline Aortic in sufficiency $\geq 2$ grade & - & - \\
\hline
\end{tabular}

Table 2. Technical characteristics of the TAVI procedure.

\begin{tabular}{ccc}
\hline Characteristics & Fréquency & Pourcentage (\%) \\
Ilio-fémoral & Look first & 100 \\
Other & 46 & - \\
& - & 100 \\
Local anesthesia and/or sédation & Type of anesthesia & - \\
General anesthesia & 46 & \\
& - & 93 \\
Edwards-Sapien & Type of the valve & 6.5 \\
Medtronic Core Valve & 43 & 63 \\
& 3 & 34 \\
23 & Diameter of the valve & 6.5 \\
26 & 29 & 97.8 \\
29 & 14 & 3 \\
\hline
\end{tabular}


On post-TAVI ultrasonography, LVEF averaged 57\%, Mean AVA was $1.48 \pm$ $4.3 \mathrm{~cm}^{2}$, MTAG was $13.8 \pm 5 \mathrm{mmHg}$, and severe PAH (>60 mmHg) was found in $4 \%$ of cases. Table 3 compares the pre- and post-TAVI echocardiographic data.

The complication rate was $17 \%(\mathrm{n}=8)$, mainly atrioventricular blocks $6.5 \%(\mathrm{n}$ $=3$ ) and local bleeding at the puncture site $6.5 \%(n=3)$.

The mean follow-up was 946 days (median $=1007.5$ days), mean follow-up death rate was $30.4 \%(n=14)$, of which $11 \%(n=5)$ died in the first year after TAVI. The causes of death were non-cardiac in $57 \%(n=8)$ of cases, cardiac in $29 \%(n=4)$ of cases and not known in $14 \%(n=2)$ of cases. The different types of complications related to TAVI and causes of death outside the hospital period are summarized in Table 4.

\section{Discussion}

The AS evolves slowly until the first symptoms appear. The functional surface of

Table 3. Comparison of Echocardiographic Data Pre and Post TAVI.

\begin{tabular}{cccc}
\hline Echocardiographic Features & Pre-TAVI & Post-TAVI & P \\
LVEF (\%) average & 56.5 & 57 & 0.99 \\
AVA $\left(\mathrm{cm}^{2}\right) \pm$ standard deviation & $0.66 \pm 0.14$ & $1.48 \pm 4.3$ & 0.44 \\
MTAG $(\mathrm{mmHg}) \pm$ standard deviation & $46.8 \pm 15.5$ & $13.8 \pm 5$ & 0.03 \\
severe PAH & $21.7 \%$ & $4 \%$ & 0.05 \\
Aortic in sufficiency $\geq 2$ grade & - & $1 / 46(2 \%)$ & - \\
\hline
\end{tabular}

Table 4. Complications related to TAVI and causes of death outside the hospital period.

\begin{tabular}{|c|c|c|}
\hline & Frequency & Pourcentage (\%) \\
\hline \multicolumn{3}{|l|}{ Type of complication } \\
\hline Conductive disorders with implantation of a Pace maker & 3 & 6.5 \\
\hline Tamponed & 1 & 2 \\
\hline Cardiac surgery under extra corporeal circulation & - & - \\
\hline First vascular complication leading to surgery or stent & 1 & 2 \\
\hline Hemorrhagic complication requiring transfusion and/or surgery & 3 & 6.5 \\
\hline Stroke & - & - \\
\hline \multicolumn{3}{|c|}{ Cause of mortalityoutside the hospitalperiod } \\
\hline Fracture of the femoral neck & 2 & 4 \\
\hline Septicshock & 1 & 2 \\
\hline Liver cancer & 1 & 2 \\
\hline Kidney cancer & 1 & 2 \\
\hline Malnutrition & 1 & 2 \\
\hline Heart failure & 3 & 6.5 \\
\hline Pace Maker Infection & 1 & 2 \\
\hline Not known & 2 & 4 \\
\hline
\end{tabular}


the valve decreases progressively causing the increase in left ventricular filling pressures. The mortality is $50 \%$ at 2 years in untreated patients from the onset of the first symptoms [6]. Survival declines when AS becomes very tight [7] [8]. Mean survival is less than 12 months after the first episode of cardiac decompensation. The combination of stage III or IV dyspnea, left ventricular dysfunction and mitral insufficiency further aggravates mortality with a 3-year survival of less than $20 \%$ [9]. Echocardiography is a key examination, it can confirm the diagnosis and search for associated valvulopathies.

TAVI has taken an important place in the management of calcified AS of the elderly in France and worldwide [10] thanks to the improvement of the technique (decrease of the device size (14F), improvement of the prostheses), improved operator experience (lack of systematic predilatation, better sizing of prostheses by measuring aortic CT diameter), and excellent results in patients contraindicated for surgery, at high risk, or at intermediate risk [11] [12] [13]. The European Society of Cardiology recommends TAVI [1] in symptomatic patients contraindicated for aortic valve replacement surgery or in patients over 75 years at high or intermediate risk (STS or EuroSCORE II $>4 \%$ or Logistic EuroSCORE I $>10 \%$ ) or with comorbidities not taken into account by the risk scores (frail patients or having undergone a first thoracotomy, or with reduced mobility) and for whom the femoral approach is possible (Grade IB) [14] [15] [16] [17].

In this study we found that our patients were at high surgical risk with a high Logistic EuroScore, a high prevalence of diabetes (nearly $10 \%$ of Reunion Islanders are diabetic according to French National Institute of Statistics and Economic Studies 2012), and renal failure. The femoral route was used in $100 \%$ of our patients. The femoral route is the most used and gives the best results [18] [19] [20]. The results were at least as good as those of France TAVI [20] with a primary success rate of $97.8 \%$. There was almost immediate clinical improvement in post TAVI with a significant decrease in MTAG $(P=0.03)$, and severe PAH $(P=0.05)$. Mean AVA and MTAG were relatively high in post TAVI compared to France TAVI data [20]. This may reflect to the use of smaller valves tailored to our patients who have smaller aortic rings in relation to their smaller size. The complication rate was low; only one case of significant aortic leakage (2\%), the rate of atrioventricular block requiring the implantation of a pacemaker was $6.5 \%$ in our series and $17.5 \%$ in France TAVI [20], one of the major complications of many studies [21] [22] [23].

Only one case of femoral artery dissection and three cases of localized hemorrhages at the puncture site were observed. The widespread adoption of scanner for the selection of vascular pathways and the increasing experience of operators in the management of vascular access have reduced the incidence of complications. The incidence of major vascular complications in current TAVI practice is now $<5 \%$ [24]. There were no cases of stroke in our study. In France TAVI stroke rate was $1.6 \%$ and $3.4 \%$ to $4.8 \%$ in the literature [25] [26]. Mean 
hospital stay was relatively short in our study and comparable to France-TAVI [20]. The mortality rate was $30.4 \%$ for an average follow-up of 946 days, and the causes of mortality were non-cardiac in more than half of the cases. The results of our study are encouraging and consistent with recent literature data and with the France TAVI registry [27] [28].

\section{Limitations of Our Study}

The main limitation of this study is the small sample size.

\section{Conclusion}

The TAVI experience of SCH is positive with a high success rate, a low complication rate, and acceptable mid-term mortality.

\section{Conflicts of Interest}

The authors do not declare any conflict of interest.

\section{References}

[1] Baumgartner, H., Falk, V., Bax, J.J., et al. (2017) ESC/EACTS Guidelines for the Management of Valvular Heart Disease. European Heart Journal, 38, 2739-2791. https://doi.org/10.1093/eurheartj/ehx391

[2] Nishimura, R.A. (2002) Cardiology Patient Pages. Aortic Valve Diseas. Circulation, 106, 770-772. https://doi.org/10.1161/01.CIR.0000027621.26167.5E

[3] Baumbach, H., Ahad, S., Rustenbach, C., et al. (2017) Conventional versus Transapical Aortic Valve Replacement: Is It Time for Shift in Indications? The Thoracic and Cardiovascular Surgeon, 65, 212-217. https://doi.org/10.1055/s-0036-1586491

[4] Ludman, P.F., Moat, N., De Belder, M.A., et al. (2015) Transcatheter Aortic Valve Implantation in the United Kingdom: Temporal Trends, Predictors of Outcome, and 6-Year Follow-Up: A Report from the UK Transcatheter Aortic Valve Implantation (TAVI) Registry, 2007 to 2012. Circulation, 131, 1181-1190. https://doi.org/10.1161/CIRCULATIONAHA.114.013947

[5] Allahwala, U.K., Hansen, P.S., Danson, E.J., et al. (2016) Transcatheter Aortic Valve Implantation: Current Trends and Future Directions. Future Cardiology, 12, 69-85. https://doi.org/10.2217/fca.15.73

[6] Bouma, B.J., et al. (1999) To Operate or Not on Elderly Patients with Aortic Stenosis: The Decision and Its Consequences. Heart, 82, 143-148. https://doi.org/10.1136/hrt.82.2.143

[7] Iung, B., et al. (2003) A Prospective Survey of Patients with Valvular Heart Diseases in Europe: The Euro Heart Survey on Valvular Heart Disease. European Heart Journal, 24, 1231-1243. https://doi.org/10.1016/S0195-668X(03)00201-X

[8] Vahanian, A., et al. (2012) Guidelines on the Management of Valvular Heart Disease (Version 2012) the Joint Task on the Management of Valvular Heart Disease of European Society of Cardiology and European Association for Cardio-Thoracic Surgery. European Heart Journal, 33, 2451-2496.

[9] Stewart, B.F., et al. (1997) Clinical Factors Associated with Calcific Aortic Valve Disease. Cardiovascular Health Study. Journal of the American College of Cardiology, 29, 630-634. https://doi.org/10.1016/S0735-1097(96)00563-3 
[10] Neylon, A., Ahmed, K., Mercanti, F., Sharif, F. and Mylotte, D. (2018) Trans Catheter Aortic Valve Implantation: Status Update. Journal of Thoracic Disease, S3637S3645. https://doi.org/10.21037/jtd.2018.10.34

[11] Smith, C.R., Leon, M.B., Mack, M.J., et al. (2011) Transcatheter versus Surgical Aortic-Valve Replacement in High-Risk Patients. The New England Journal of Medicine, 364, 2187-2198. https://doi.org/10.1056/NEJMoa1103510

[12] Adams, D.H., Popma, J.J., Reardon, M.J., et al. (2014) Transcatheter Aortic-Valve Replacement with a Self-Expanding Prosthesis. The New England Journal of Medicine, 370, 1790-1798. https://doi.org/10.1056/NEJMoa1400590

[13] Leon, M.B., Smith, C.R., Mack, M.J., et al. (2016) Transcatheter or Surgical Aortic-Valve Replacement in Intermediate-Risk Patients. The New England Journal of Medicine, 374, 1609-1620. https://doi.org/10.1056/NEJMoa1514616

[14] Leon, M.B., et al. (2010) Transcatheter Aortic Valve Implantation for Aortic Stenosis in Patients Who Cannot Undergo Surgery. The New England Journal of Medicine, 363, 1597-1607. https://doi.org/10.1056/NEJMoa1008232

[15] Thyregod, H.G.H., et al. (2015) Transcatheterversus Surgical Aortic Valve Replacement in Patients with Severe Aortic Valve Stenosis: 1-Year Results from the AllComers NOTION Randomized Clinical Trial. Journal of the American College of Cardiology, 65, 2184-2194.

[16] Deeb, G.M., et al. (2016) 3-Year Otcoumes in High-Risk patients Who Underwent Surgical or Transcatheter Aortic Valve Replacement. Journal of the American College of Cardiology, 67, 2565-2574.

[17] Siontis, G.C.M., et al. (2016) Transcatheter Aortic Valve Implantation Versus Surgical Aortic Valve Replacement for Treatment of Severe Aortic Stenosis: A Meta-Analysis of Randomized Trials. European Heart Journal, 37, 3503-3512. https://doi.org/10.1093/eurheartj/ehw225

[18] Reardon, M.J., et al. (2017) Surgical or Transcatheter Aortic Valve Replacement in Intermediate-Risk Patients. The New England Journal of Medicine, 376, 1321-1331.

[19] Siontis, G.C., Praz, F., Pilgrim, T., et al. (2016) Implantation de la valve aortiquetranscathéter par rapport au remplacement chirurgical de la valve aortique pour le traitement de la sténoseaortiquesévère: Uneméta-analysed'essaisrandomisés. European Heart Journal, 37, 3503-3512.

[20] Auffret, V., et al. (2017) Temporal Trends in Transcatheter Aortic Valve Replacement in France: France 2 to France TAVI. Journal of the American College of Cardiology, 70, 42-55.

[21] Stortecky, S., Brinks, H., Wenaweser, P., Huber, C., Pilgrim, T., Windecker, S., et al. (2011) Transcatheter Aortic Valve Implantation or Surgical Aortic Valve Replacement as Redo Procedure After Prior Coronary Artery Bypass Grafting. The Annals of Thoracic Surgery, 92, 1324-1331.

https://doi.org/10.1016/j.athoracsur.2011.05.106

[22] Ducrocq, G., Al-Attar, N., Himbert, D., Messika-Zeitoun, D., Iung, B., Descoutures, F., et al. (2012) Early and Mid-Term Outcomes in Patients Undergoing Transcatheter Aortic Valve Implantation after Previous Coronary Artery Bypass Grafting. European Journal of Cardio- Thoracic Surgery, 41, 499-504. https://doi.org/10.1093/ejcts/ezr041

[23] Gandji, W., Azarnoush, K., Mulliez, A., Innorta, A., Farhat, M., Combaret, N., et al. (2016) Impact des techniques interventionnellesdans le traitement de la valvulopathieaortique après revascularisationmyocardiquechirurgicalepréalable. Annales de Cardiologie et d' Angéiologie, 65, 7-14. https://doi.org/10.1016/j.ancard.2015.01.006 
[24] Athappan, G., Gajulapalli, R.D., Tuzcu, M.E., et al. (2016) Une revue systématiquesur la sécurité des valvulesaortiquestranscathéter de deuxièmegénération. EuroIntervention, 11, 1034-1043. https://doi.org/10.4244/EIJV11I9A211

[25] Feldman, T.E., Reardon, M.J., Rajagopal, V., et al. (2018) Effet du remplacementvalvulaireaortiquetranscathéter par expansion mécaniqueou auto-expansible sur la mortalité et les événementscliniquesindésirablesmajeurs chez les patients à haut risqueatteints de sténoseaortique: Essaicliniquerandomisé REPRISE III. The Journal of the American Medical Association, 319, 27-37.

[26] Reardon, M.J., Van Mieghem, N.M., Popma, J.J., et al. (2017) Remplacementvalvulaireaortique chirurgical outranscathéter chez les patients à risqueintermédiaire. The New England Journal of Medicine, 376, 1321-1331. https://doi.org/10.1056/NEJMoa1700456

[27] Gilard, M., Eltchaninoff, H., Donzeau-Gouge, P., et al. (2016) Late Outcomes of Transcatheter Aortic Valve Replacement in High-Risk Patients: The FRANCE-2 Registry. Journal of the American College of Cardiology, 68, 1637-1647.

[28] Carroll, J.D. (2016) TAVR Prognosis, Aging, and the Second TAVR Tsunami: Insights from France. Journal of the American College of Cardiology, 68, 1648-1650. https://doi.org/10.1016/j.jacc.2016.08.005

\section{Abbreviations}

\section{AS: Aortic Stenosis;}

TAVI: Transcatheter Aortic Valve Implantation;

SCH: Sainte Clotilde Hospital;

AVA: Aortic Valve Area;

LVEF: Systolic Ejection Fraction of the Left Ventricle;

MTAG: Mean Trans Aortic Gradient;

PAH: Pulmonary Arterial Hypertension;

Euro SCORE: European System for Cardiac Operative Risk Evaluation;

STS: Society of Thoracic Surgeons. 